Retraction

\title{
Retracted: Initiation of Triangle Zones by Delamination, Shear, and Compaction at the Front of Fold-and-Thrust Belts
}

\author{
Journal of Earthquakes \\ Received 28 July 2016; Accepted 28 July 2016 \\ Copyright ( 2016 Journal of Earthquakes. This is an open access article distributed under the Creative Commons Attribution \\ License, which permits unrestricted use, distribution, and reproduction in any medium, provided the original work is properly \\ cited.
}

At the request of the authors, the article titled "Initiation of Triangle Zones by Delamination, Shear, and Compaction at the Front of Fold-and-Thrust Belts" [1] has been retracted. Yves Leroy of the Ecole Normale Supérieure was missing from the author list and was instead listed in the Acknowledgements. Prof. Leroy was the major contributor and supervised the first author, and the article was submitted without his knowledge.

\section{References}

[1] C. Liu and Y. Shi, "Initiation of triangle zones by delamination, shear, and compaction at the front of fold-and-thrust belts," Journal of Earthquakes, vol. 2016, Article ID 6302546, 21 pages, 2016. 

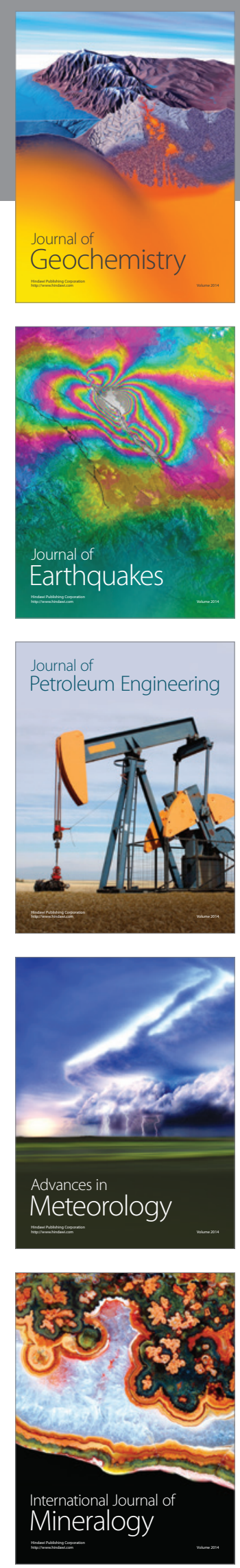
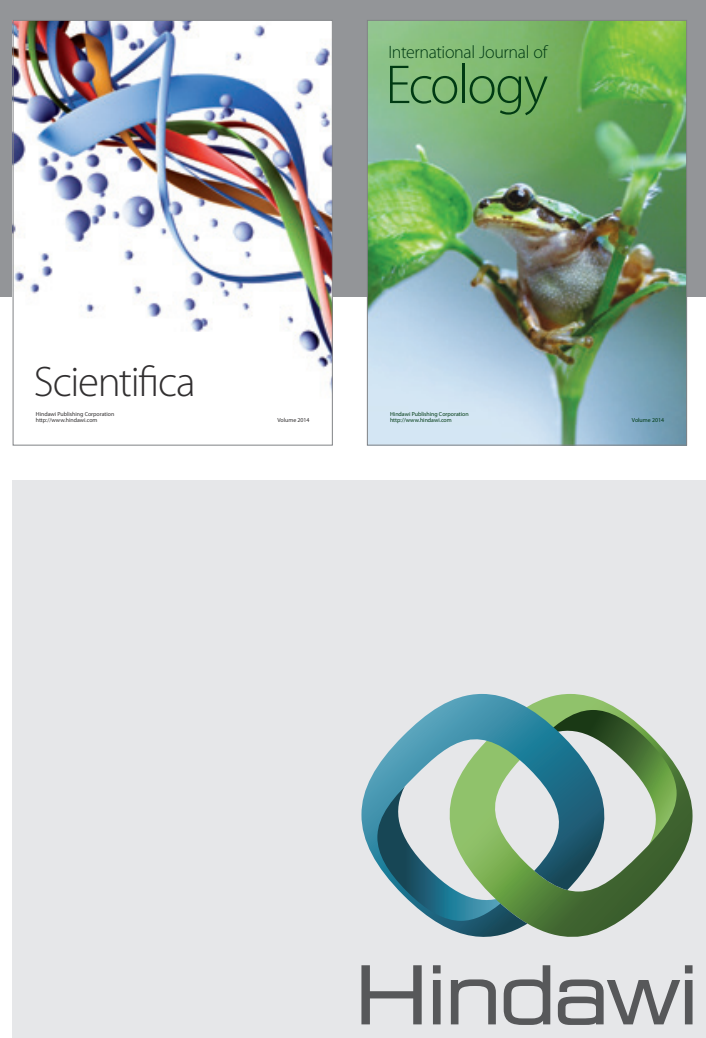

Submit your manuscripts at

http://www.hindawi.com
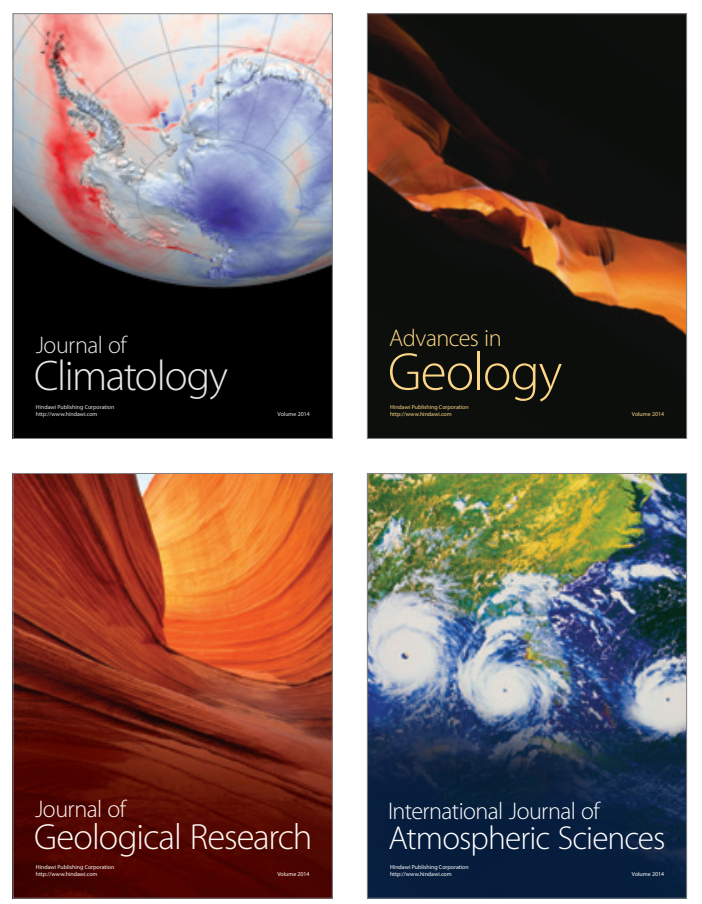

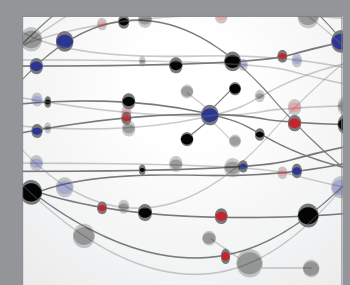

The Scientific

\section{World Journal}
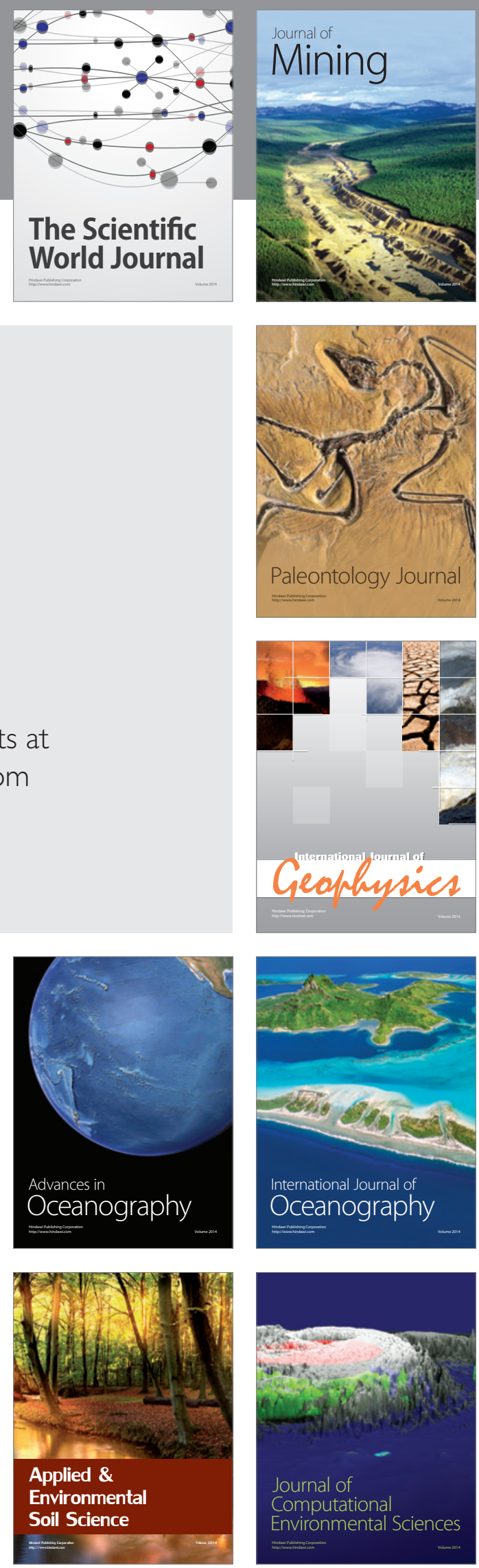